Ciência Florestal, Santa Maria, v. 21, n. 4, p. 609-618, out.-dez., 2011

ISSN 0103-9954

\title{
AVALIAÇÃO DA INTENSIDADE LUMINOSA NO DESENVOLVIMENTO INICIAL DE LEUCENA (Leucaena leucocephala (Lam.) de Wit.)
}

\author{
EVALUATION OF THE EFFECTS OF LIGHT INTENSITIES UPON THE INITIAL DEVELOPMENT \\ OF LEUCENA (Leucaena leucocephala (Lam.) de Wit.)
}

Vanessa Decker ${ }^{1}$ Élcio Silvério Klosowski² Ubirajara Contro Malavasi ${ }^{3}$ Alexandre Nunes ${ }^{4}$

\begin{abstract}
RESUMO
O objetivo deste trabalho foi avaliar o efeito de diferentes intensidades luminosas, proporcionadas por sombreamento natural em área de preservação permanente, no desenvolvimento inicial de mudas de Leucaena leucocephala (Lam.) de Wit. O experimento foi conduzido na área de Captação 1 do Serviço Autônomo de Água e Esgoto (SAAE) de Marechal Cândido Rondon - PR, de 11 de setembro a 20 de novembro de 2007. As sementes, coletadas de árvores matrizes provenientes da região de Toledo-PR, foram submetidas à quebra de dormência com água a $80^{\circ} \mathrm{C}$ e semeadas em número de dez por vaso, estes foram distribuídos na área obedecendo ao delineamento inteiramente casualizado (DIC) com 13 tratamentos correspondentes às intensidades luminosas e 10 repetições (vasos), totalizando 130 vasos. Após 10 e 20 dias da semeadura foram realizados desbastes, deixando-se 5 e 3 plântulas por vaso, respectivamente. Sessenta dias após a semeadura, as mudas foram coletadas para avaliações biométricas como: diâmetro do caule, altura da planta, número de folhas, área foliar, massa seca da raiz, caule e folha. Os resultados foram analisados por meio de análise de variância seguida de teste $\mathrm{F}$ e análise de regressão demonstrando existir uma relação polinomial de quarta ordem dos parâmetros biométricos com intensidade luminosa, em que a resposta da leucena foi mais significativa para intensidades iguais a 642 Lux e 2273 Lux, aproximadamente, que representam 0,90 e 3,19\% da Irradiância Solar Global. Por se tratar de uma espécie pioneira, a leucena tenderia a apresentar um comportamento de maior desenvolvimento quando submetida a maiores intensidades luminosas, no entanto, os resultados obtidos durante 60 dias em que as mudas foram avaliadas, indicam também um bom desenvolvimento das mudas sob baixas intensidades luminosas, podendo ser considerada, nas condições em que o experimento foi conduzido, uma espécie secundária. Desta forma, este resultado também pode explicar o fato desta espécie ser considerada invasora.
\end{abstract}

Palavras-chaves: germinação; leucena; regressão polinomial; intensidade luminosa.

\begin{abstract}
The study objective was to evaluate the effects of light intensities upon the initial development of Leucaena leucocephala seedlings. The study was conducted inside a preservation area around a drinking water well used to supply Marechal Cândido Rondon residents from September 11th to November $20^{\text {th }}, 2007$. The seeds collected from mature leucaena trees located on an adjacent county (Toledo) went through break dormancy in vases, in water at 80 Celsius degrees and sown by using 10 units per vase. The vases were distributed in the area obeying an entirely randomized design with 13 light intensities (treatments) and 10 replications
\end{abstract}

1. Bióloga, Mestre em Agronomia, Programa de Pós-graduação em Agronomia, Centro de Ciências Agrárias, Universidade Estadual do Oeste do Paraná, Campus de Marechal Candido Rondon, Rua Nossa Senhora da Luz, 363, CEP 85903-080, Toledo (PR).nessadecker@yahoo.com.br

2. Engenheiro Agrônomo, Dr., Professor Adjunto do Programa de Pós-graduação em Agronomia, Centro de Ciências Agrárias, Universidade Estadual do Oeste do Paraná, Campus de Marechal Candido Rondon, Rua Pernambuco,1777, CEP 85960-000, Toledo (PR). elciosk1@yahoo.com.br

3. Engenheiro Agrônomo, Dr., Professor Adjunto do Programa de Pós-graduação em Agronomia, Centro de Ciências Agrárias, Universidade Estadual do Oeste do Paraná, Campus de Marechal Candido Rondon, Rua Pernambuco,1777, CEP 85960-000, Toledo (PR). umala@unioeste.com.br

4. Engenheiro Agrônomo, Rua Nossa Senhora da Luz, 363, CEP 85903-080, Toledo (PR). alexandre_nunes@hotmail.com

Recebido para publicação em 14/01/2009 e aceito em 3/11/2010 
(vases), adding up to 130 vases. Five and two seedlings per vase were left after thinning executed 10 and 20 days after the sowing, respectively. Sixty days after the sowing, the seedlings were collected for the measurements of the stem diameter, the plant height, the number and area of leaves as well as the root, the stem and the leaf biomasses. Results indicated that there is a polynomial relationship of the fourth order between biometric parameters and light intensity; the highest significances were calculated for intensities of 643 and 2273 Lux indicating that leucaena can be considered pioneering and tolerant to direct sunlight.

Keywords: germination; leucena; polynomial regression; luminous intensity.

\section{INTRODUÇÃO}

Em decorrência da destruição de florestas tropicais, o interesse em estudos sobre estes ecossistemas tem crescido, principalmente em se tratando de sucessão ecológica, a qual contribui para o entendimento de adaptação de espécies florestais ao ambiente. Algumas espécies têm potencial para alterar sistemas naturais, estando ligado à capacidade das plantas de se naturalizarem, apresentando características que promovam maior disseminação, como o alto poder de dispersão de sementes e de germinação, rebrota, períodos longos de floração e frutificação e capacidade de sobreviverem em ambientes degradados ou florestas já existentes.

Dentre as espécies florestais que vêm sendo estudadas, quanto a sua adaptação a novos ambientes, está a leucena (Leucaena leucocephala (Lam.) de Wit), originária da América Central e presente em todas as regiões tropicais do mundo. É pertencente à família FABACEAE que apresenta raiz pivotante, muito bem desenvolvida e profunda, as folhas são compostas, alternas, bipinadas, com até $20 \mathrm{~cm}$ de comprimento, as flores são alógamas, apresentam coloração branca ou amarela, dispostas em inflorescências capituladas esféricas, ou ligeiramente elípticas, de $2 \mathrm{~cm}$ de diâmetro, o fruto é um legume de coloração castanha quando maduro (LORENZI et al., 2003).

Do ponto de vista econômico, a leucena pode ser utilizada na alimentação de animais devido as suas propriedades e palatabilidade, emprego na produção de carvão, dentre outras aplicações. Esta espécie é muito utilizada em reflorestamentos e tem a capacidade de tolerar diferentes tipos de solos, apresentando boa fixação de nitrogênio (ABBAS et al., 2001), crescimento rápido com maturação precoce e fácil adaptação a diferentes condições climáticas (PARROTTA, 1992).

As condições climáticas proporcionadas por diferentes tipos de ecossistemas são as mais variadas possíveis. Em um ambiente florestal, a intensidade luminosa é um dos elementos que apresenta maior variabilidade espacial e temporal. Considerando que a quantidade de energia luminosa requerida pelos vegetais para o seu desenvolvimento também é variável e age diretamente na produção fotossintética é possível, segundo Maciel et al., (2002), classificálos em tolerante e não a altas intensidades luminosas. Portanto, a intensidade luminosa observada no interior de uma floresta pode se constituir, então, em um fator limitante para certas espécies adaptadas às condições que o ambiente oferece.

Neste sentido, o presente trabalho teve por objetivo avaliar o efeito de diferentes intensidades luminosas proporcionadas pelo sombreamento natural de floresta em área de preservação, no desenvolvimento inicial da Leucaena leucocephala (Lam.) de Wit.

\section{MATERIAL E MÉTODOS}

$\mathrm{O}$ experimento foi conduzido na pequena mata presente na Área de Preservação Ambiental da Área de Captação 1 do Serviço Autônomo de Água e Esgoto (SAAE), localizada na confluência das Avenidas Rio Grande do Sul e Irio Jacob Welp do município de Marechal Cândido Rondon - Oeste do Estado do Paraná.

De acordo com a EMBRAPA (2006) o solo predominante é do tipo latossolo vermelho eutroférrico. E seu clima é classificado segundo Köppen, do tipo Cfa, subtropical com chuvas bem distribuídas durante o ano e verões quentes. As temperaturas médias do trimestre mais frio variam entre 17 e $18^{\circ} \mathrm{C}$, do trimestre mais quente entre $28 \mathrm{e}$ $29^{\circ} \mathrm{C}$ e a anual entre 22 e $23^{\circ} \mathrm{C}$. Os totais de chuva variam entre 1600 e $1800 \mathrm{~mm}$ com trimestres mais úmidos apresentando totais variando entre 400 e 500 mm (IAPAR, 2008).

Para avaliar o efeito da intensidade luminosa no desenvolvimento inicial da leucena, foram escolhidos alternadamente 89 pontos de observação, de acordo com a distribuição do dossel vegetal dentro da Área de Preservação Permanente. Estes pontos foram distribuídos seguindo uma disposição 
em rede com bordadura de $20 \mathrm{~m}$ a partir das laterais da área, obedecendo a um delineamento inteiramente casualizado (DIC) (Adaptação de SOUZA, 1996).

As medidas de intensidade luminosa foram tomadas por meio de um luxímetro digital marca Instrutherm modelo LD 205 - LUX METER. O equipamento foi posicionado na horizontal a uma distância de aproximadamente $1 \mathrm{~m}$ em relação à superfície do solo. As observações foram realizadas na data de 18 de abril de 2007, no período entre 11 e 13 horas.

Na Área de captação 1 foram observados valores de intensidades luminosas entre 102 e 2519 Lux, que foram agrupados em intervalos de classe conforme se observa no histograma (Figura 1).

Foram escolhidos 13 pontos para a avaliação da intensidade luminosa sobre o crescimento inicial de mudas de leucena com intensidades iguais ou próximas ao ponto médio da classe de frequência, obedecendo a uma relação de menor para maior quantidade de luz, cujos valores foram 172, 286, $612,642,955,1227,1420,1537,1813,1884,2273$, 2338, 2519 Lux.

Estes valores foram comparados aos da Irradiância Solar Global observados na estação climatológica de Marechal Cândido Rondon por meio do piranômetro da marca KIPP \& ZONEN modelo CM6B de primeira classe.

Os elementos meteorológicos observados no local do experimento foram temperaturas do ar e os totais de chuva. As temperaturas foram medidas por

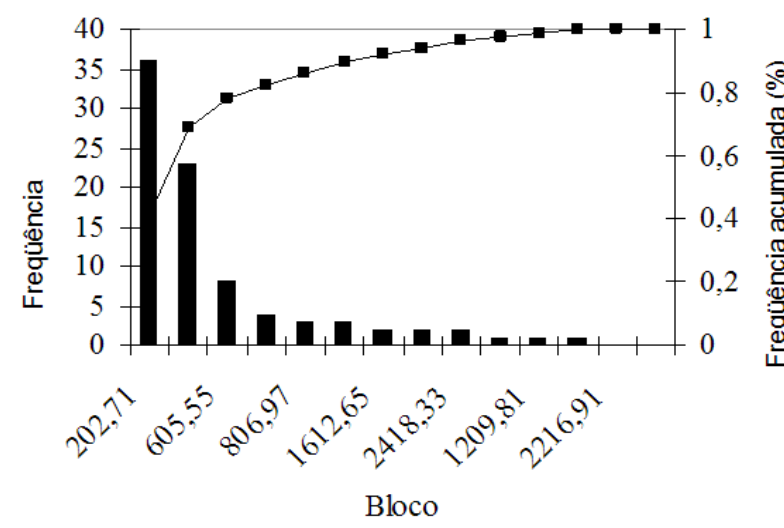

FIGURA 1: Histograma de intensidades luminosas, observadas na Área de Preservação. Marechal Cândido Rondon. (18/04/2007).

FIGURE 1: Histogram of light intensities, observed in the Preservation Area. 'Marechal Candido Rondon' (04/18/2007). meio de termômetro de máxima e mínima modelo capela, todos os dias às 9 horas. Este equipamento foi instalado em um abrigo meteorológico de madeira à altura de $1,5 \mathrm{~m}$.

Os totais diários de chuva foram coletados em pluviômetro de acrílico com capacidade de 110 $\mathrm{mm}$, instalado próximo ao abrigo meteorológico a uma altura em relação à superfície do solo de 1,5 m.

As sementes utilizadas no experimento foram coletadas de 3 árvores matrizes de Leucaena leucocephala (Lam.) de Wit., com idade de 5 anos e diâmetro de copa de aproximadamente $3 \mathrm{~m}$. As árvores matrizes encontram-se plantadas em propriedade rural, localizada em Linha Doutor Ernesto, no município de Toledo na região Oeste do Paraná. O solo predominante é do tipo latossolo vermelho eutroférico (EMBRAPA, 2006).

As sementes foram selecionadas manualmente, sendo escolhidas as que apresentavam estar visivelmente sadias, dando um total de 1500 . Antes da semeadura foi realizada a quebra de dormência das sementes utilizando-se água a $80^{\circ} \mathrm{C}$ por 5 minutos, conforme a metodologia proposta por Teles, 2000.

O solo utilizado no experimento foi coletado na Fazenda Experimental Professor Doutor Antônio Carlos dos Santos Pessoa, da Universidade Estadual do Oeste do Paraná, de Marechal Cândido Rondon. Apesar da análise química do solo foi verificado que não haveria necessidade de adição de qualquer tipo de adubação.

A semeadura ocorreu no dia 11 de setembro de 2007, sendo as sementes semeadas diretamente em vasos de polipropileno com diâmetros de base de $23 \mathrm{~cm}$, de borda de $26 \mathrm{~cm}$ e altura de $8 \mathrm{~cm}$. Cada vaso recebeu $5 \mathrm{~kg}$ de solo peneirado, sendo as sementes depositadas a uma profundidade de 1,5 $\mathrm{cm}$, dispostas em um circulo em número de dez por vaso, posteriormente cobertas por uma fina camada de solo. Cada tratamento recebeu 10 vasos que foram transportados para dentro do dossel vegetal e dispostos em circulo sobre o solo nos pontos das referidas intensidades luminosas selecionadas.

Após, foi realizada a primeira rega nos vasos até se atingir a capacidade de campo que ocorreu com a adição de $250 \mathrm{ml}$ de água. Durante o tratamento, as regas foram realizadas uma vez por semana, caso não ocorressem chuvas, até obter-se novamente a capacidade de campo e esta lâmina de água não foi adicionada aos totais de chuva.

O primeiro desbaste foi realizado após 10 dias da semeadura, deixando-se nos vasos cinco 
mudas mais vigorosas e com maior crescimento. Após 20 dias de semeadura, foi realizado novo desbaste, mantendo-se três mudas que apresentavam no mínimo um a dois pares de folhas formadas, totalizando 30 mudas por tratamento.

As avaliações do crescimento das mudas foram feitas, 60 dias após a semeadura (adaptação de FONSECA et al., 2002), utilizando-se dos seguintes parâmetros: Diâmetro do Caule (DC) (mm), Comprimento da Raiz (CR) (cm) e Altura da Planta (AP) (cm), Número de Folhas (NF) e Área Foliar (AF) $\left(\mathrm{cm}^{2}\right)$, utilizando-se da ferramenta computacional QUANT 2002 Versão 1.0.1. Para a determinação da $\mathrm{AF}$ as folhas foram fotografadas e a imagem digital foi armazenada em computador. A ferramenta computacional reconhece as imagens por possuírem centenas ou milhares de cores, sendo então convertidas a duas cores, vermelho e branco. Cada uma destas cores representa um tipo de imagem, o vermelho corresponde à folha e o branco ao fundo da imagem. A quantidade de pigmentos vermelhos produzidos na imagem é computada pelo sistema, fornecendo assim a área foliar.

Os dados de Massa Seca da Parte Aérea (MSPA), Massa Seca da Raiz (MSR) e Massa Seca do Caule (MSC) foram obtidos após secagem em estufa de circulação forçada a $65^{\circ} \mathrm{C}$, até atingir o peso constante. A pesagem do material foi feita por balança semianalítica de marca Marte ${ }^{\circledR}$, modelo AS5500C.

O delineamento experimental adotado foi o inteiramente casualizado, apresentando 13 tratamentos correspondentes à intensidade luminosa e 10 repetições por tratamento. Cada repetição correspondeu a um vaso.

A partir dos dados coletados procedeu-se a análise de variância seguida pelo Teste $\mathrm{F}$, análise de regressão e Correlação de Pearson. Todas as análises foram feitas pelo programa computacional SAEG 9.0.

\section{RESULTADOS E DISCUSSÃO}

$\mathrm{Na}$ Figura 2 podem ser observados os valores diários de temperatura máxima e mínima correspondente ao período da semeadura até a retirada das plantas para análise. Neste período foram observadas temperaturas máximas que variaram de 22 a $37^{\circ} \mathrm{C}$ e mínima de 8 a $26^{\circ} \mathrm{C}$. Os valores médios para a temperatura máxima e mínima foram de 30,3 e $20,5^{\circ} \mathrm{C}$, respectivamente.

Apesar de tolerar amplo espectro de temperatura, a leucena tem seu crescimento

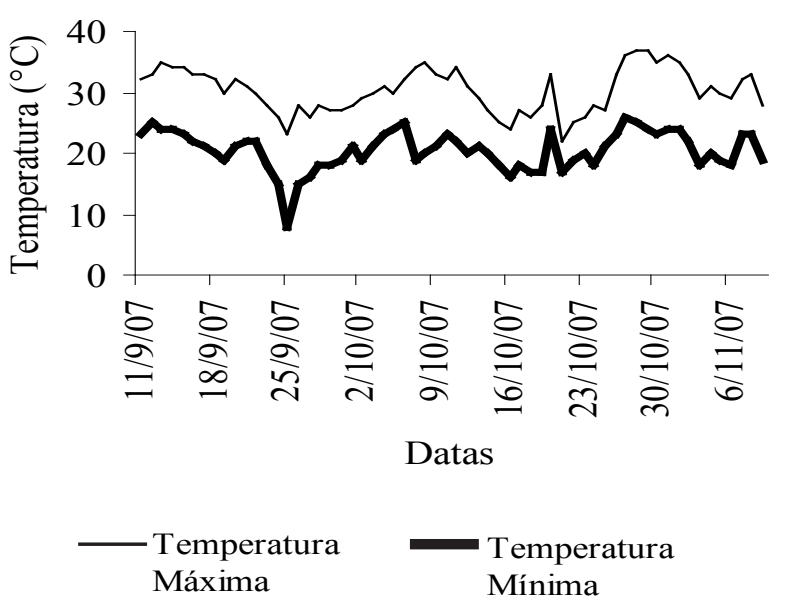

FIGURA 2: Valores diários de temperatura máxima e mínima observados na Área de Preservação. Marechal Cândido Rondon (11/09 a 10/11/2007).

FIGURE 2: Observed daily values of maximum and minimum temperature in the Preservation Area 'Marechal Candido Rondon' (09/11 the 11/10/2007).

seguramente restringido para temperaturas inferiores a $16^{\circ} \mathrm{C}$ (PARROTTA, 1992).

A menor temperatura do ar registrada no período experimental foi de $8^{\circ} \mathrm{C}(25 / 09)$, embora o efeito negativo sobre o crescimento não tenha sido observado, mesmo estando à temperatura muito abaixo do limite suportado pela espécie.

As temperaturas médias diárias do ar mantiveram-se sempre acima de $20^{\circ} \mathrm{C}$, que, de acordo com Borges et al., (1997) e Oliveira e Medeiros Filho (2007), promovem condições mais adequadas para a germinação da leucena $\left(25\right.$ e $\left.35^{\circ} \mathrm{C}\right)$ em câmara de germinação.

Na Figura 3 são observados os totais de chuva durante o período experimental na Área de Captação 1 do SAAE-MCR, cuja lâmina total de chuva foi de $221 \mathrm{~mm}$. O valor máximo foi observado no dia 22/09, apresentando um total de $121 \mathrm{~mm}$ e a média diária foi de $3,62 \mathrm{~mm}$.

De acordo com a Figura 3, o total de precipitação pluvial foi de $221 \mathrm{~mm}$. As regas permitiram manter o solo dos vasos na capacidade de campo o que possibilitou a sobrevivência e o desenvolvimento das mudas, considerando que o total de precipitação registrada na área correspondeu a $88,4 \%$ do limite inferior que permite a sobrevivência da espécie que, segundo Lima \& Evangelista (2008), é de $250 \mathrm{~mm}$. De acordo com estes autores, no 


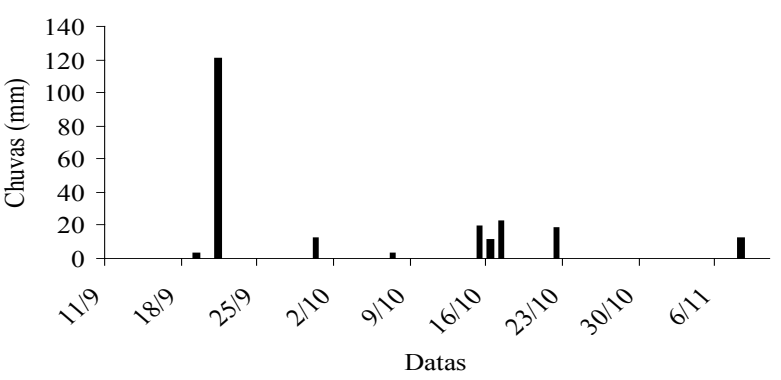

FIGURA 3: Total de precipitação pluviométrica diária observada na Área de Preservação. Marechal Cândido Rondon (11/09/2007 a 10/11/2007).

FIGURE 3: Total daily rainfall observed in the Preservation Area 'Marechal Candido Rondon' (09/11/2007 the 11/10/2007).

entanto, a leucena desenvolve-se muito bem em ambientes com pluviosidade entre 600 e $1700 \mathrm{~mm}$ e Larcher (2000) destaca que nos primeiros estádios de desenvolvimento, a necessidade hídrica das plantas é maior e ela pode comprometer o desenvolvimento e o vigor.

A intensidade luminosa observada na área experimental foi comparada aos valores obtidos de Irradiância Solar Global $\left(765,37 \mathrm{Wm}^{2}\right)$ no dia 18 de abril de 2007, na estação climatológica de Marechal Cândido Rondon, no período entre 11 e 13 horas. Considerando este valor como referência e a equivalência de 93 Lux para $1 \mathrm{Wm}^{2}$ podese representar a relação entre IL e RG como valor percentual conforme se observa na Tabela 1 .

Partindo de valores de IL, a quantidade de radiação solar incidente na Área de Captação 1 do SAAE-MCR variou de 1,84 a 27,09 $\mathrm{Wm}^{2}$ que correspondeu entre 0,24 e $3,53 \%$ em relação à Radiação Solar Global observada na estação climatológica.

Estes resultados demonstraram que grande parte da radiação solar em uma floresta, é interceptada pelos componentes do dossel como galhos, ramos e folhas. Neste sentido, os resultados obtidos neste trabalho se assemelharam aos obtido por Chazdon \& Fetcher (1984) citado por Souza (1996), que afirma ser a quantidade de radiação incidente sobre a vegetação no interior de uma floresta de 0,4 e 3,8\% daquela observada em exposição a pleno sol.

Na tabela 2 estão apresentados os quadrados médios e os respectivos níveis de significância da análise de variância obtidos pelo teste $\mathrm{F}$ para parâmetros biométricos.

As médias de diâmetro do caule (DC),
TABELA 1: Valores de intensidade luminosa (IL) e a relação com a Irradiância Solar Global (RG) observada na Área de Preservação. Marechal Cândido Rondon .

TABLE 1: Light Intensities (IL) values and their relationship with the global solar irradiation (IL/GSI) in the Preservation Area 'Marechal Candido Rondon'.

\begin{tabular}{ccc}
\hline $\mathrm{IL}(\mathrm{Lux})$ & $\mathrm{IL}\left(\mathrm{Wm}^{2}\right)$ & $\mathrm{IL} / \mathrm{RG}(\%)$ \\
\hline 172 & 1,84 & 0,24 \\
286 & 3,08 & 0,4 \\
613 & 6,58 & 0,86 \\
642 & 6,91 & 0,90 \\
955 & 10,27 & 1,34 \\
1227 & 13,19 & 1,72 \\
1420 & 15,27 & 1,99 \\
1537 & 16,52 & 2,15 \\
1813 & 19,49 & 2,54 \\
1884 & 20,26 & 2,64 \\
2273 & 24,44 & 3,19 \\
2338 & 25,14 & 3,28 \\
2519 & 27,09 & 3,53 \\
\hline
\end{tabular}

comprimento da raiz (CR), altura da planta (AP), número de folhas (NF), área foliar (AF), massa seca da raiz (MSR), massa seca do caule (MSC) e massa seca da folha (MSF) apresentaram diferenças estatísticas a $1 \%$ de significância em relação às diferentes intensidades luminosas a que as plantas foram submetidas.

Pôde-se verificar que as diferentes intensidades luminosas a que a leucena foi submetida causaram efeito sobre seu desenvolvimento. O modelo de análise que melhor se ajustou para explicar essa relação foi o de regressão polinomial quadrático. Nas Figuras 4 e 5 estão representadas as curvas que apontam dois picos de maior efeito das diferentes intensidades luminosas (IL) sobre o diâmetro do caule e a altura da planta. Segundo Carneiro (1995), o aumento do diâmetro do caule, com a altura da muda, corresponde a um melhor desenvolvimento da planta após o seu transplante.

$\mathrm{Na}$ Figura 4 observa-se que a intensidade luminosa, a que as mudas foram submetidas, exerce 
TABELA 2: Análise de variância para diâmetro do caule (DC), comprimento da raiz (CR), altura da planta (AP), número de folhas (NF), área foliar (AF), massa seca da raiz (MSR), massa seca do caule (MSC) e a massa seca da folha (MSF), em plantas de leucena.

TABLE 2: Variance analyses to the stem diameter (DC), root length (CR), plant height (AP), leaf number (NF), foliar area (AF), as well as root (MSR), stem (MSC) and leaf (MSF) in leucena.

\begin{tabular}{lccccccccc}
\hline CV & GL & DC & CR & AP & NF & AF & MSR & MSC & MSF \\
\hline Trat. & 12 & $4,3^{*}$ & $1612,0^{*}$ & $1289,2^{*}$ & $157,4^{*}$ & 3209,2 & $0,1^{*}$ & $0,4^{*}$ & $2,6^{*}$ \\
Erro & 78 & 9,8 & 871,8 & 348,1 & 49,3 & 836,4 & 0,2 & 0,2 & 0,8 \\
\hline Média & & 1,7 & 10,4 & 15,6 & 3,9 & 13,3 & 0,3 & 0,3 & 0,3 \\
CV & & 21,1 & 32,0 & 13,5 & 20,5 & 24,7 & 16,2 & 14,9 & 32,9 \\
\hline
\end{tabular}

Em que: * = significativo a $5 \%$ de probabilidade pelo teste $\mathrm{F}$.

$D C=1,478+0,0018 l u x-0,0000036 l u x^{2}+2,385 l u x^{3}-4,686 l u x 4$ $\mathbf{R}=\mathbf{5} \%$

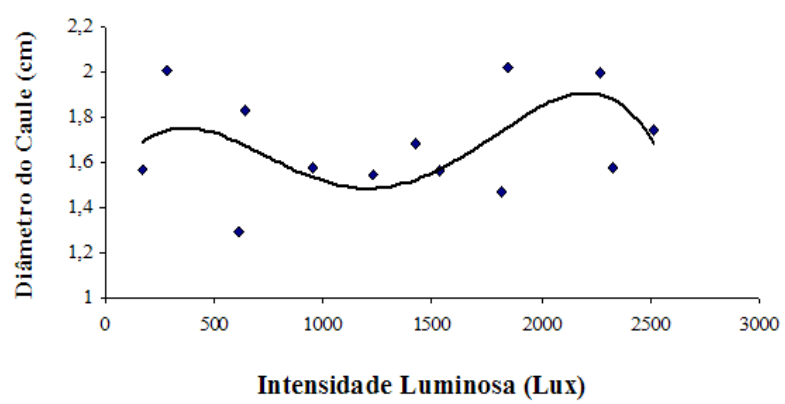

FIGURA 4: Relação entre o diâmetro médio do caule (DC) da leucena com a intensidade luminosa.

FIGURE 4: Relationship between average stem diameters of leucena seedlings with the light intensity.

\section{$\mathrm{AP}=0,028+0,085 \operatorname{lux}-0,000133 \operatorname{lux}^{2}+7,592 \mathrm{lux} x^{3}-1,408 \mathrm{lux} 4$ $\mathbf{R}^{2}=\mathbf{4 2 , 2} \%$}

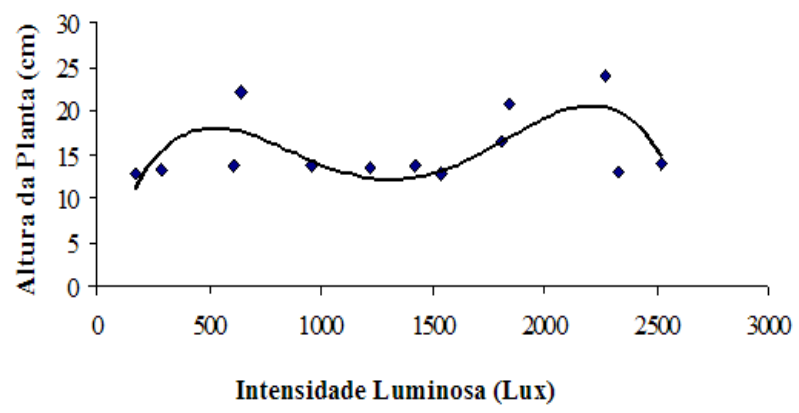

FIGURA 5: Relação entre a altura média da planta (AP) da leucena com a intensidade luminosa.

FIGURE 5: Relationship between the average plant heights of leucena seedlings with the light intensity. pouco efeito sobre o diâmetro do caule $\left(\mathrm{R}^{2}=0,0538\right)$. Os maiores diâmetros médios (2 e 2,2 cm) foram obtidos para 286 e 1847 Lux, respectivamente e o menor (1,29 e 1,47 cm) para 612 e 1813 Lux.

A relação altura da planta também se ajustou a este modelo, com $\mathrm{R}^{2}$ de $0,422(\mathrm{P}<0,0001)$ indicando efeito mais pronunciado da quantidade de luz disponível sobre a altura da planta do que sobre o diâmetro do caule. As maiores alturas da planta de 22,01 e 23,91 cm foram observadas para intensidades luminosas de 642 e 2273 Lux. Estes valores de intensidade luminosa correspondem a 0,9 e 3,19\% da Irradiância Solar Global observada a pleno sol. As menores alturas (12,71 e 12,72 cm) foram encontradas para 172 e 1537 Lux, respectivamente.

A altura da planta observada para 642 e 2273

Lux mostra um adequado desenvolvimento inicial das mudas. De acordo com o que recomenda Parrotta (1992), as mudas apresentam um tamanho inicial adequado para serem transplantadas quando, após 10 semanas de semeadura, portarem $20 \mathrm{~cm}$ de altura.

Os resultados obtidos por Fanti \& Perez (2003), no entanto, mostram que mudas de Adenanthera pavoniana L., quando submetidas por 60 dias à exposição de 60 e 30\% de luminosidade, não sofreram influência significativa da intensidade luminosa sobre a altura da planta, que variou de 7,17 a 8,67 cm. Portanto, as respostas das plantas em relação à intensidade luminosa variam de acordo com a espécie.

Nas Figuras 6 e 7 estão apresentadas as relações entre intensidade luminosa e massa seca da raiz. As médias do CR e da MSR foram maiores para as mesmas intensidades luminosas. Para o CR os maiores valores foram de 18 e $18,6 \mathrm{~cm}$, enquanto para a MSR foram de 0,38 e 0,40 g nas IL de 642 e 2273 Lux, respectivamente. Estes valores de IL correspondem a 0,9 e 3,19\% da RG, respectivamente. 
As menores médias para CR foram de 4,97 e $6,25 \mathrm{~g}$ para IL de 172 e 2328 Lux e para a MSR foi de $0,29 \mathrm{~g}$ quando submetidas a intensidades de 955 e 1537 Lux. $\mathrm{O}$ coeficiente de determinação $\left(\mathrm{R}^{2}\right)$ foi positivo para ambos os parâmetros, destacando-se o valor obtido para $\mathrm{CR}$ de $0,415(\mathrm{P}<0,0001)$ em relação à $\mathrm{MSR}$, que foi de $0,183(\mathrm{P}<0,0002)$.

A leucena, por ser boa fixadora de nitrogênio, tem como característica a raiz principal pivotante de maior comprimento, o que explica o melhor ajuste de CR em relação à MSR. Este resultado contradiz Larcher (2000) que afirma que a quantidade de luz não exerce tanta influência sobre o desenvolvimento da raiz, quanto a que é exercida pelos totais de chuva.

No caso da MSR, o efeito das intensidades luminosas foi menor que o observado para o

\section{$C R=-11,319+0,115 \operatorname{lux}-0,000175 \operatorname{lu} x^{2}+9,833 \operatorname{lux} x^{3}-1,818 \operatorname{lux} 4$} $R^{2}=\mathbf{4 1 , 5 \%}$

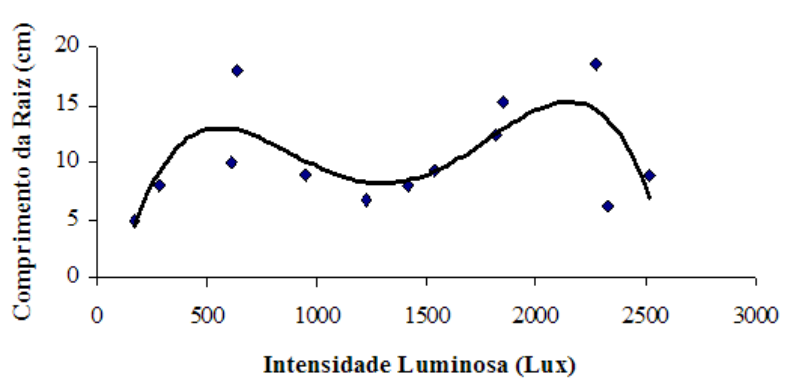

FIGURA 6: Relação entre o comprimento médio da raiz (CR) de leucena com a intensidade luminosa.

FIGURE 6: Relationship between average root heights of leucena seedlings with the light intensity.

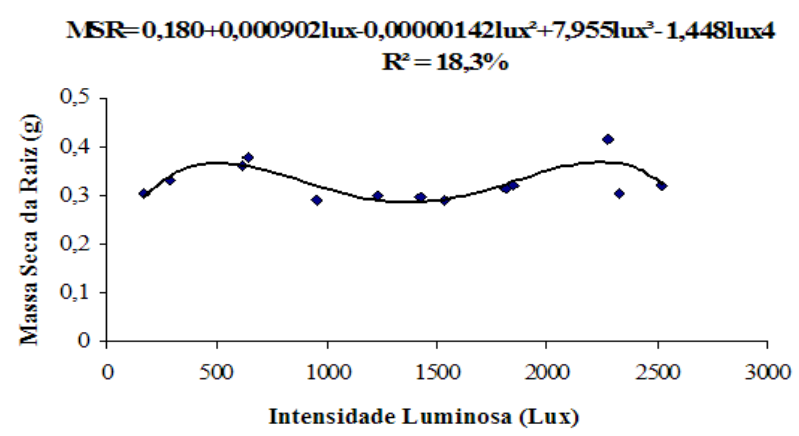

FIGURA 7: Relação entre a massa seca média da raiz (MSR) de leucena com a intensidade luminosa.

FIGURE 7: Relationship between average root dry mass of leucena seedlings with the light intensity. comprimento da raiz. Segundo Carneiro (1995) isto pode estar relacionado à medida deste parâmetro nas mudas, que por apresentarem raízes finas com muitos pêlos absorventes, geralmente tornam as medições de sua massa quase desprezíveis.

Como se verificou para os demais parâmetros biométricos estudados, a relação entre NF, AF, MSF e IL também se ajustou a um polinômio de quarta potência, que pode ser observado nas Figuras 8, 9 e 10, respectivamente. De acordo com a Figura 8, as maiores médias do NF de 6,57 e 5, 81 por muda foram encontradas em intensidades de 642 e 2273 Lux, que correspondem a 0,90 e $3,19 \%$ da Irradiância Solar Global observada a pleno sol, respectivamente. Os menores valores médios foram de 2,40 e 2,47 folhas por mudas encontradas para intensidades de 172 e 1537 Lux, respectivamente.

Como se depreende na Figura 9, os maiores valores de área foliar foram de 23,68 e 23,64 $\mathrm{cm}^{2}$ para 642 Lux e 2338 Lux, respectivamente. Em relação à Irradiância Solar Global observada naquela data e horário, estes valores de intensidade luminosa correspondem a 0,90 e 3,28\%, respectivamente. Em menores valores de área foliar de 6,07 e $7,75 \mathrm{~cm}^{2}$ foram observados 1537 e 1813 Lux.

Tal como foi observado para o parâmetro número de folhas por muda, os maiores valores de massa seca da folha (Figura 10) foram observados em 642 e 2273 Lux e correspondem a 0,67 e 0,69 g, respectivamente. Nas intensidades luminosas de 2328 e 2519 Lux foram observados os menores valores de

\section{$\mathrm{NF}=-2,653+0,036 \mathrm{lux}-0,0000562 \mathrm{lux} x^{2}+3,198 \mathrm{lux} x^{3}-5,939 \mathrm{lux} 4$} $\mathbf{R}^{\mathbf{2}}=\mathbf{5 7} \%$

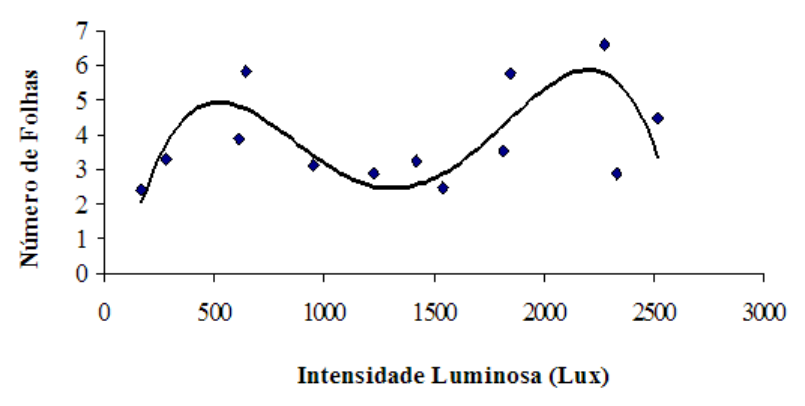

FIGURA 8: Relação entre o número médio de folhas (NF) da leucena com a intensidade luminosa.

FIGURE 8: Relationship between average leaf numbers of leucena seedlings with the light intensity. 


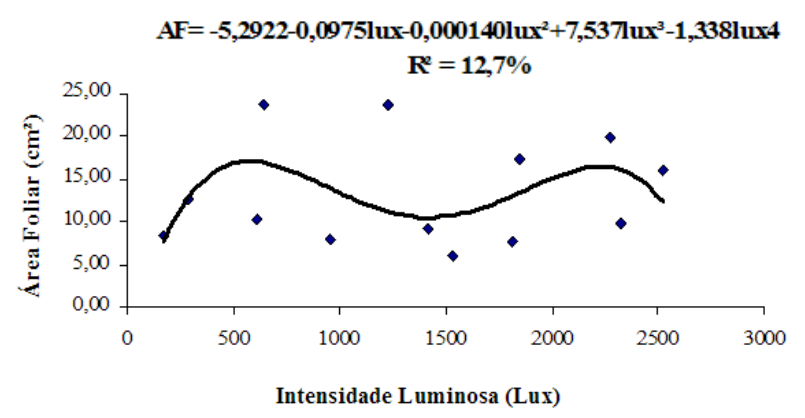

FIGURA 9: Relação entre a área foliar média (AF) da leucena com a intensidade luminosa.

FIGURE 9: Relationship between average leaf areas of leucena seedlings with the light intensity.

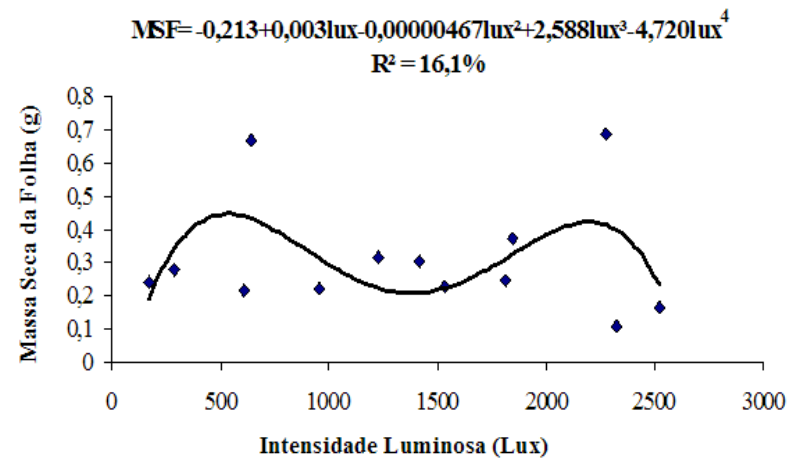

FIGURA 10: Relação entre a massa seca média da folha (MSF) da leucena com a intensidade luminosa.

FIGURE 10: Relationship between average leaf dry mass of leucena seedlings with the light intensity.

massa seca da folha de 0,10 e $0,16 \mathrm{~g}$, respectivamente. Como se comprova a partir da área e da massa seca, a folha apresenta uma tendência de maior desenvolvimento em condições de luminosidade para plantas do tipo heliófitas. Esta constatação conforme afirma Campos e Uchida (2002), é uma resposta que indica uma maneira da planta compensar a falta de luminosidade.

Os resultados obtidos neste trabalho são similares aos obtidos por Fanti e Perez (2003) que encontraram para mudas de Adenanthera pavonina L. submetidas a $70 \%$ de sombreamento aos 60 dias após a semeadura uma área foliar de $87,67 \mathrm{~cm}^{2}$.

A massa seca do caule (Figura 11) foi de 0,46 e $0,48 \mathrm{~g}$ para as intensidades luminosas de 642 e 2273 Lux, respectivamente. Para estes parâmetros biométricos, os menores valores foram de $0,27 \mathrm{e} 0,28 \mathrm{~g}$ em 955 e 1813 Lux, respectivamente. Estes resultados

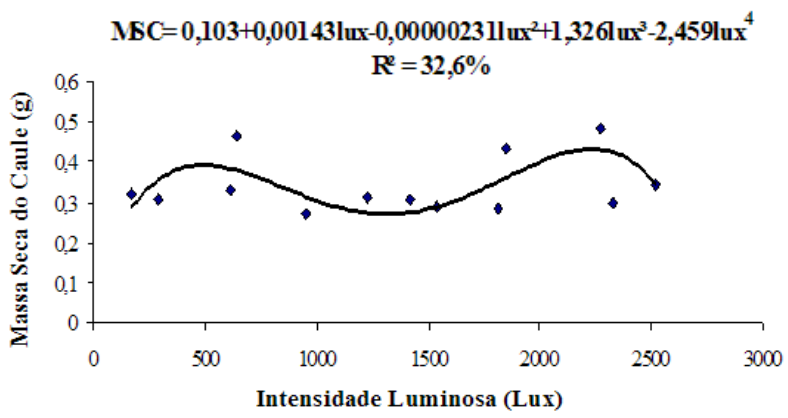

FIGURA 11: Relação entre a massa seca média do caule (MSC) da leucena com a intensidade luminosa.

FIGURE 11: Relationship between the average stem dry masses of leucena seedlings with the light intensity.

diferem daqueles encontrados por Almeida et al., (2005) testando alterações morfológicas e alocação de biomassa em plantas jovens de Maclura tinctoria (L.), Senna macranthera (Collad.), Hymenaea courbaril L., Acacia mangium Willd. Quando plantas desta espécie foram submetidas a pleno sol, 30 e $50 \%$ de sombreamento não apresentando diferenças significativas na distribuição de matéria seca para o caule.

De acordo com os resultados obtidos por Campos \& Uchida (2002), plantas de Jacaranda copaia (Aubl.) D. Dom. e Hymenaea courbaril L. também não apresentaram diferenças significativas na massa seca do caule quando submetidas a diferentes intensidades luminosas. Entretanto, para a espécie Ochroma lagopus (Cav. Ex. Lam.) Urban. a maior massa seca do caule quando submetida a $30 \%$ de sombreamento.

Na Tabela 3, encontram-se os resultados da Correlação de Pearson, obtidos para parâmetros biométricos como diâmetro do caule (DC), comprimento da raiz (CR), altura da planta (AP), número de folhas (NF), área foliar (AF) e massa seca da raiz (MSR), caules (MSC) e folhas (MSF) e a Intensidade Luminosa (IL) nas diferentes condições de iluminação natural observadas na Área de Captação 1 do SAAE-MCR no período de setembro a novembro de 2007.

Pode-se verificar que o DC da leucena apresentou correlação positiva e significativa com AP, NF, AF, MSC e MSF. A correlação deste parâmetro com o CR, MSR e IL não foi significativa.

Em se tratando do CR, este apresentou correlação positiva e significativa com todos os outros parâmetros. Os resultados mais expressivos 
TABELA 3: Coeficiente de correlação de Pearson entre parâmetros biométricos de mudas de leucena. Marechal Cândido Rondon (10/11/2007).

TABLE 3: Pearson's correlation between the biometric parameters of leucena seedlings and light intensity. Marechal Cândido Rondon (11/10/2007).

\begin{tabular}{|c|c|c|c|c|c|c|c|c|}
\hline & $\mathrm{DC}$ & CR & AP & NF & $\mathrm{AF}$ & MSR & MSC & MSF \\
\hline CR & $0,155^{\mathrm{ns}}$ & & & & & & & \\
\hline AP & $0,315 *$ & $0,739 *$ & & & & & & \\
\hline $\mathrm{NF}$ & $0,385 *$ & $0,706 *$ & $0,816^{*}$ & & & & & \\
\hline $\mathrm{AF}$ & $0,255 * *$ & $0,235 *$ & $0,518 *$ & $0,543 *$ & & & & \\
\hline MSR & $0,048^{\mathrm{ns}}$ & $0,489 *$ & $0,345 *$ & $0,375 *$ & $0,265 * *$ & & & \\
\hline MSC & $0,262 * *$ & $0,575 *$ & $0,668 *$ & $0,688 *$ & $0,523 *$ & $0,392 *$ & & \\
\hline MSF & $0,345 *$ & $0,675 *$ & $0,737 *$ & $0,638 *$ & $0,545 *$ & $0,417 *$ & $0,616 *$ & \\
\hline IL & 0,131 ns & $0,252 * *$ & $0,305^{* *}$ & $0,314 * *$ & 0,101 ns & $0,038^{\text {ns }}$ & $0,199^{*}$ & 0,029 ns \\
\hline
\end{tabular}

Em que: $*=$ significativo a $5 \%$ de probabilidade; $* *=$ significativo a $1 \%$ de probabilidade; ${ }^{\text {ns }}=$ não significativo; $\mathrm{DC}=$ diâmetro do caule; $\mathrm{CR}=$ comprimento da raiz; $\mathrm{AP}=$ altura da planta; $\mathrm{NF}=$ número de folhas; $\mathrm{AF}=$ área foliar; $\mathrm{MSR}=$ massa seca da raiz; $\mathrm{MSC}=$ massa seca do caule; $\mathrm{MSF}=$ massa seca de folhas; $\mathrm{IL}=$ Intensidade Luminosa.

foram verificados com a AP e NF, demonstrando que as raízes têm fundamental importância na absorção de água e nutrientes do substrato pelas mudas e, dependendo da quantidade que lhe é fornecida, interfere no seu desempenho de crescimento e desenvolvimento.

Portela et al. (2001), trabalhando com mudas de Clitoria fairchildiana Howard., encontraram para o parâmetro comprimento da raiz, valores inferiores em mudas submetidas a pleno sol, que não diferiram estatisticamente daquelas a 30,50 e $70 \%$ de sombreamento. Para o incremento em altura, este foi maior quando a planta permaneceu em radiação solar direta.

Campos e Uchida (2002), avaliando três espécies amazônicas, não encontraram diferença significativa para as médias de altura e comprimento da raiz em mudas de Jacaranda copaia (Aube.) D. Don. quando estas foram submetidas durante 63 dias a diferentes intensidades luminosas. Quando a exposição foi de 173 dias, as mudas submetidas a $70 \%$ de sombreamento apresentaram maiores alturas. Em contrapartida, as mudas a $30 \%$ de sombreamento apresentaram maior número de folhas. As mudas submetidas a uma condição de maior sombreamento tenderam a apresentar relação parte aérea/sistema radicular superior às demais.

Para a leucena, a AP também apresentou correlação positiva com todas as variáveis, sendo a mais expressiva com relação ao NF. Entre estes dois parâmetros existe uma estreita relação, pois há tendência de um aumento no NF à medida que aumenta a AP. Esta observação também foi confirmada por Silva et al., (2007) que encontraram em mudas de Hymenea parvifolia Huber., submetidas por 105 dias a $70 \%$ de sombreamento, maiores valores de AP $(59,86 \mathrm{~cm})$ associados ao maior NF (10 folhas).

AAF apresentou boa correlação com a MSR, MSC e MSF, não sendo significativa para a IL. Esta relação não significativa com o IL pode ser explicada pelo fato da planta ter sofrido alguma limitação nas trocas gasosas, ou por temperatura, ou ainda pela disponibilidade de água, pois, sem esta interferência, a fotossíntese realizada pela folha, acompanha linearmente a disponibilidade de radiação até o ponto de saturação (LARCHER, 2000).

Como se observou, todos os parâmetros avaliados apresentaram dois picos encontrados para intensidades luminosas de 642 Lux e 2273 Lux, aproximadamente, que representam 0,90 e $3,19 \%$ da Irradiância Solar Global. Por se tratar de uma espécie pioneira, a leucena tenderia a apresentar um comportamento de maior desenvolvimento quando submetida a maiores intensidades luminosas, no entanto, os resultados obtidos durante os 60 dias em que as mudas foram avaliadas, indicam um bom desenvolvimento das mudas sob baixas intensidades luminosas, podendo ser considerada secundária. Desta forma, este resultado também pode explicar o fato desta espécie ser considerada invasora.

Contudo, considerando que as sementes utilizadas neste experimento foram provenientes de árvores adultas, distintas, é possível que os resultados obtidos possam estar relacionados à ocorrência de populações ou de subpopulações.

\section{CONCLUSÃO}

Os resultados da análise demonstraram existir uma relação polinomial de quarta ordem dos 
parâmetros biométricos com a intensidade luminosa, em que a resposta da leucena foi mais significativa quando submetida a intensidades de 642 e 2273 Lux, estes valores de IL correspondem a 0,90 e 3,19\%, respectivamente, da Radiação Solar Global observada em estação climatológica.

A partir dos dados correlacionados podese perceber que é necessário um maior número de evidências, para se obter informações conclusivas a respeito do comportamento da leucena em relação à quantidade de luz disponível. Por se tratar de um ambiente natural, alguns fatores externos podem ter contribuído para os diferentes resultados encontrados.

As respostas a estes baixos valores de iluminação demonstram, nas condições em que o experimento foi conduzido, ter a leucena potencial para se estabelecer como uma espécie secundária, mesmo sendo considerada uma espécie pioneira.

\section{REFERÊNCIAS BIBLIOGRÁFICAS}

ABBAS, M. et al. Intercroping of sesbania (Sesbania sesban) and leucaena (Leucaena leucocephala) with five annual grasses under semi-arid conditions as affected by inoculation with specific rhizobia and associative diazotrophs. Agronomie, v. 21, n. 6-7, p. 517-525, Sept./Nov. 2001.

ALMEIDA, S. M. Z. et al. Alteração morfológica e alocação de biomassa em plantas jovens de espécies florestais sob diferentes condições de sombreamento.

Ciência Rural, Santa Maria, v. 35, n. 1, p. 62-68, jan/ fev 2005.

BORGES, E. E. L.; BORGES, R. C. G.; PAULA, N. F. Efeito da temperatura e do estresse hídrico na germinação de sementes de fedegoso (Senna macranthera (Collad.) Irwin e Barn) e de Leucaena leucocephala (Lam.) de Wit. Revista Brasileira de Sementes, Lavras, v.19, n. 2, p. 155-158, jun. 1997.

CAMPOS, M. A. A.; UCHIDA, T. Influência do sombreamento no crescimento de mudas de três espécies florestais amazônicas. Pesquisa Agropecuária Brasileira, Brasília, v. 37, n. 7, p. 281 288, mar. 2002.

CARNEIRO, J. G. A. Produção e controle de qualidade de mudas florestais. Curitiba: UFPR, FUPEF; Viçosa: CAMPOS, UENF, 1995.

EMBRAPA - Empresa Brasileira de Pesquisa Agropecuária. Sistema de Classificação dos solos. 2 . ed. Rio de Janeiro: Embrapa Solos, 2006.

FANTI, S. C.; PEREZ, S. C. Influência do sombreamento artificial e da adubação química na produção de mudas de Adenanthera pavonina.
Ciência Florestal, Santa Maria, v.13, n.1, p 49-56, 2003.

FONSECA, É. P. et al. Padrão de qualidade de mudas de Trema micrantha (L.) Blume. Produzidas sobre diferentes períodos de sombreamento. Revista Árvore, Viçosa, v. 26, n. 4, p. 515-523, jul./ago. 2002. IAPAR. Cartas climáticas do Paraná. Disponível em: <http://200.201.27.14/Site/ Sma/Cartas Climaticas/Classificacao_Climatica.htm $>$. Acessado em: 30 de maio de 2008.

LARCHER, W. Ecofisiologia Vegetal. São Carlos: RiMa, 2000.

LIMA, J. A.; EVANGELISTA, J. R. Leucena (Leucaena leucocephala) Disponível em: <www. editora.ufla.br/BolExtensao/pdfBE/bol_50.pdf $>$. Acessado em: 18/04/2008.

LORENZI, H. et al. Árvores Exóticas no Brasil: madeiras, ornamentais e aromáticas. Nova Odessa, Instituto Plantarum, 2003.

MACIEL,M. N. M. et. al. Efeito da radiação solar na dinâmica de uma floresta. Revista Ciências Exatas e Naturais, Curitiba, v. 4, n. 1, jan/jun. 2002.

OLIVEIRA, A. B.; MEDEIROS FILHO, S. Influência de tratamentos pré-germinativos, temperatura e luminosidade na germinação de sementes de leucena cv. Cunningham. Revista Brasileira de Ciências Agrárias, Recife, v. 2, n. 4, p. 268-274, out./dez. 2007.

PARROTTA, J. A. Leucaena leucocephala (Lam.) de Wit. Departament of agriculture, Forest Service, Southern Forest, Experimental Station. 8 p. SO-ITFSM-52, New Orleans, LA: U.S, 1992.

PORTELA, R. C. Q. et al. Crescimento inicial de mudas de Clitoria fairchildiana Howard e Peltophorum dubiun (Sprenge) Taub em diferentes condições de sombreamento. Ciência Florestal, Santa Maria, v. 11, n. 2, p. 163-170, 2001.

SILVA, R. R. et al. Desenvolvimento inicial de plântulas de Theobroma grandiflorun (Willd. Ex spreng) Schum. sob influência de sombreamento. Acta Amazônica, Manaus, v. 37, n. 3, p. 365-370, 2007.

SOUZA, R. P. Germinação, crescimento, atividade fotossintética e translocação de compostos de carbono em espécies florestais tropicais: estudo comparativo da influência de sombreamento natural. Tese (Doutorado em Ciências Biológicas)Universidade Estadual de Campinas, Campinas, 1996. TELES, M. M. et al. Método de quebra de dormência em sementes de Leucaena leucocephala (Lam.) de Wit. Revista Brasileira de Zootecnia, Viçosa, v. 29, n. 2, p. 387-391, mar./abr. 2000.

Ci. F1., v. 21, n. 4, out.-dez., 2011 